\section{THE CONSERVATION AND MANAGEMENT OF THE CULTURAL HERITAGE OF THAILAND: THE DRAFTING OF THE CHARTER}

\section{Weeraphan Shinawatra}

\begin{abstract}
This paper is an attempt to explain problems of cultural heritage conservation and management in Thailand due to the neglect of the State and the weakness of the society in understanding and protecting their cultural heritage especially the "folk culture" against globalization. The paper also points out that the impending Thailand Charter for cultural heritage conservation and management is the key solution to counterbalance today's threats. Non-government organizations should take the lead in drafting the Charter with full public participation. Meanwhile local cultural heritage organizations which are at risk should immediately respond, with all stakeholders involved, before it is too late.
\end{abstract}

\section{Thai Culture: Origins and Development}

Before the establishment of Thailand as a nation in the land of Suvarnbhumi (Land of Gold), the realm abounded with ethnic and cultural diversity as it was located on the maritime trade route between India and China. At that time, using sea and land routes, Southeast Asians developed trading relations. The primary sea route followed the coastline (Intharawut, 2005: 32). In the coastal area, there were trading and social interactions among various nations with different customs and traditions, different religious beliefs, and cultural practices influenced by Khom, Hindu and Islamic cultures and mainly by Indian and Chinese civilizations. Since then, the region has become a confluence of different cultures and civilizations. In fact, in prehistoric times there was also association among different groups of peoples in Southeast Asia. During the Metal Age (about 3500 years ago) early settlers in different parts of Southeast Asia shared cultural practices (Intharawut 2005: 32).

In the past, Thailand was officially called Siam. According to Jit Phumisak, the author of a book about the etymology of the terms Siam, Thai, Lao, and Khom, and the social characteristics of ethnonyms, the name Siam might have gradually evolved, over thousands of years, from Sarm, Sarn, Same, Siem, Sayam, and Seam. These were names used to refer to the ancient Tai by neighboring nations. Phumisak's work presents a systematic study of language to increase understanding of early Thai history and the origin of Thais (Kasetsiri, 'Preface', in Jit Phumisak, 2001:11).

Over the long history of the nation, Thai culture has been developed from a range of small agricultural societies. In former times, a number of early agricultural villages-influenced by various civilizations that existed in the regionshared their customs and wisdom. Later, tribal villages formed into urban communities that eventually clustered into small empires and kingdoms across the territory. The rising and falling of these small kingdoms and empires followed an unclear sequence, and there is uncertainty and discontinuity in their chronology. As for the superior kingdoms, including Dvaravati, Srivijaya, Haripunjaya, Sukhothai, Lopburi or Lawo, AyodhayaSupanabhumi, Krungsri Ayudthaya, and 
Rattanakosin, there are overlaps and parallel periods of supremacy. The extended kingdom of Lanna existed in parallel with several empires of later periods up to the reign of Phrachao Inthawichayanon, the $7^{\text {th }}$ ruler of Nakorn Chiang Mai. The Lanna Kingdom ended in 1886, after Chao Dararassamee XI, daughter of Phrachao Inthawichayanon, was offered to King Rama V. However, Lanna is not identified as a Thai kingdom, and its historical and archaeological significance as the origin of Thai is not included in the conventional narrative of Thai history.

The old Thai kingdoms were shaped by two societies -- Thai imperial society and Thai village society. The 'royal culture' and the 'folk culture' were connected by religious customs, especially by Buddhist practices. Furthermore, Brahman and Hindu rituals also helped to maintain the association of the two cultures, as stated below by Srisak Wallipodom (2001:4):

The royal culture is a high culture while the populace culture is a low culture, which can be called life culture. The populace culture involves ruralurban ways of life. Each group or community embraces and develops its own culture and way of life developed from learning process in order to adjust to and survive in different settlement areas. Local cultures of different places are diverse, depending on their ancestors, history, and environment. The difference between the royal culture and the populace culture is that the royal culture creates unity and similarity in society to integrate different groups together while the populace culture creates and maintains diversity to different groups in society. The royal culture exists far from common people that can perceive only its patterns and systematic symbols referred to as arts and culture while the populace culture comprehends dynamic, everchanging lifestyle and society.

It can be said that Thai culture is derived from a combination of Asian civilizations and various other cultures, including the 'folk cultures' and 'royal cultures' of the old kingdoms across the region. Thais have developed their own culture from a unique blend of different Southeast Asian cultures and influential cultures and civilizations that flowed into this region in former times. As noted by Sumet Jumsai in his book NAGA Cultural Origins in Siam and the West Pacific:

Human penetration into the continent's interior was significant, particularly in the area immediately south of the Himalayas, for at that point in time and geography there occurred a rebound of the complex fusion of the oceanmountain continent idea (as contained in the Hindu-Buddhist cosmology) back to South-East Asia where, as a result, the built environment was subjected to an unprecedented creative fervour. No doubt the Arayan [sic] invasion of northern India played a part by pushing people southeastwards, but it was primarily due to the early Indian traders that Hinduism came to the Malay Peninsula, and possibly to Emperor Asoka that Buddhism 
eventually found its way to the Chao Phraya Basin.

The rebound of this cosmography in effect completed a full cycle, and the result was that the original reflex or primary instinct was now superimposed by a secondary intellectual system based on contemplation and set rules. The response in Siam was threefold: first, a ready acceptance of the Hindu-Buddhist canon which in architecture corresponds to the formal style referred to (set rules being in any case unavoidable for the business of government); secondly, the existence side by side of the formal (secondary) and non-formal (primary) cultural elements without any apparent conflict; and thirdly, the bending of classical rules due to the irrepressible instinct of the people, giving architecture a distinct character of its own (Jumsai,1997: 79-80).

Slightly different from the Indian greeting, the traditional Thai greeting was adapted from the Hindu salutation Namaste. This illustrates the characteristic of Thais' cultural adaptation. Furthermore, several defining aspects of the Thai identity - including its alphabet, literature, performances, arts, and architecture -- adapted from Tai, Indian, Chinese, Khom, and Arabic cultures, confirm the aforementioned adaptability of Thai people.

While Thais have nurtured and maintained the 'royal cultures' and religions from past eras, 'folk cultures' have been ignored or treated as insignificant. As a result, evidence of high culture still exists in Thai society, while today's 'populace cultures' have been westernized.

\section{Cultural Heritage: the Understanding of Cultural Heritage in Thai Society}

Before the introduction of the term 'cultural heritage' into Thai society, the public was familiar with the word 'culture' as a way of life, a set of values, behavioral patterns, belief systems, traditions, and customs from the past. As a result of the post-World War II historic preservation movement, the terms 'cultural heritage,' 'preservation,' 'tangible heritage,' and 'architectural heritage' were brought into Thai society. After the war, the massive destruction of artistically, archeologically, and historically significant monuments sparked worldwide concern for the preservation of cultural heritage. Although the Athens Charter for the restoration of historic monuments was adopted in 1931, it was after World War II that the United Nations Educational, Scientific, and Cultural Organization (UNESCO, 1945) drew up several declarations, charters, and conventions to raise awareness of the world's 'cultural heritage'. Among these was the Venice Charter, drawn up in 1964 for the conservation and restoration of monuments and sites. As in several other countries, the Venice Charter has become the standard for preservation practice in Thailand. After the Venice Charter, several conservation charters --Australia's Burra Charter, the Washington Charter, the Nara Document on Authenticity, and the Chinese Charter -- were drawn up by expanding the principles of the Venice Charter and broadening the scope of preservation to safeguard the context of 
historic sites and monuments and to embrace an approach that supports the protection of 'intangible heritage', such as the local way of life, neighborhoods, communities, traditions, and customs, as 'cultural heritage' for the future.

Although many other nations have developed their own conservation charters based on the Venice Charter, the Thai Fine Arts Department has not yet developed a national charter for the cultural heritage of Thailand. Hence, the questions are: When will Thailand have a national cultural heritage conservation charter? What direction should this charter take? Should the charter cover the whole range of the country's cultural heritage, or only works of art?

\section{The Situation of Cultural Heritage in Thailand}

In the past, the Fine Arts Department was the only governmental body responsible for the protection of historical monuments and objects in Thailand. As mentioned in the previous section, the narrow definition of the term 'cultural heritage' forbids the protection of cultural resources in the country. However, the Fine Arts Department's preservation work has not been expanded to include the protection of other cultural resources due to its restricted budget and management. In addition, society's ignorance of folk culture and the tide of Western culture sweeping the country pose a risk to national cultural heritage.

Indeed, under the flood of globalization, today's Thai society swiftly absorbs foreign customs from both Western and Eastern countries. As technology is an accelerator for globalization, today's fastpaced transportation and communication have significantly influenced physical and cultural changes in Thailand. The phenomenal urban growth and internal migration have caused the society to neglect the diverse indigenous wisdom and culture. In addition, the cultural gap between urban and rural populations has increased. The nation's tangible culture has deteriorated, and local intangible culture has been weakened in the midst of the 'modern development' of the past century. Consequently, there are places with cultural intensity found in unpleasing settings, due to public ignorance and unawareness. The clutter of development has created eyesores and environmental pollution. In other words, evidence of the cultural heritage has gradually been erased from the map of Thailand as well as from Thai memories. The country is now facing the decline of its cultural capital. Cultural disruption that makes it difficult for young people to learn about the ancient roots of their culture and indigenous wisdom is another critical challenge.

As Thai society has become more complex, the term 'Thai culture' has been interpreted differently among Thai individuals and organizations, depending on their backgrounds. The diverse constituents in society, such as government, private companies, academics, and laypersons, comprehend 'Thai culture' from different standpoints, which results in a vague picture of 'Thai culture'. In comparison, perceiving the whole picture of 'Thai culture' seems like assembling an unfinished jigsaw puzzle with pieces spread out across a table. The society has been enjoying the culture of globalization, without awareness of losing of its own. In contrast, many foreign governments have, for many years, had a higher interest in and concern for enhancing the arts and cultural 
environment in their country, and as a result, they have increased funds and other support for arts and cultural research and cultural tourism.

As for the richness and diversity of Thai arts and culture, Thailand contains highpotential educational resources and tourism destinations; however, they are in crisis for lack of good management. Thailand is, indeed, a multi-level cultural reserve-with internationally, nationally and locally important heritage, but it has deteriorated partially on account of inadequate information and understanding of the indigenous cultural heritage in the government sector. For example, construction of roads through communities with cultural intensity has had a great impact on social and cultural change in the area; broad roads have become a form of social-interaction barrier for community residents and brought along with them besides traffic accidents - an eyesore of mixed-use buildings. In short, some of the so-called 'development projects' have taken away the locals' way of living and cultural identity. The limitation of urban planning laws and the immigration of labor have also caused physical transformation of neighborhoods, and altered local daily living patterns. It can be said that without social connection and cultural identity, the local sense of belonging is weakened, and here is the place where a cycle of immigration, cultural ignorance, and selfishness begin in the face of National Economic and Social Development Plan 9. In other words, the poor management of cultural resources has undermined social cohesion and threatened cultural integrity and eventually resulted in the loss of the nation's cultural capital that helps run the local administration and economy.
Therefore, Thailand should take a look at itself and ask out loud:

- Has the nation decided to desert its cultural heritage?

- What does the society want its 'cultures' to be?

- How does Thailand need to adjust itself culturally?

- Do the constituents of the society have a shared understanding of the cultures?

- How can Thailand find a balance in its cultural development today in order for it to be useful for future generations?

These issues confirm that, as for the government sector, besides cultural awareness, sufficient information on the country's cultural environment and sources is crucial for improving cultural resource management practices of each bureau. As has been done in several other countries, the nation's cultural database should be developed, and cultural information should be provided for each development project that the government offices handle. Well-conserved cultural resources will not only offer a cultural environment attractive to tourists but also provide the nation with strong cultural linkage.

The Ministry of Culture has recently been founded as a government bureau responsible for integrating cultural knowledge and managing the artistic and cultural heritage of Thailand in order to maintain the nation's cultural diversity. The Ministry has been developing cultural maps as tools for cultural resource management across the country while performing the role of a cultural coordinator among governmental offices. 


\section{A Charter for the Conservation and Management of the Cultural Heritage of Thailand: Necessity and Direction}

It is important for Thailand to find a balance between Thai culture and the culture of globalization. Over time Thai society has become a more complex society in the current of globalization. Therefore, Thais' cultural education and their well-balanced adjustment to international cultures are urgent matters if the society is to sustain and cultivate 'Thai culture' as well as reconnect 'Thai culture' to today's Thai society, like the slogan 'think global, act local'.

The value of Thailand's cultural heritage in all its diversity should be exhibited. It is essential to value extensive resources, not only historic monuments and objects. Unlike Western society with its concern for preserving tangible cultural heritage such as old buildings, urban communities, and neighborhoods, Asians have more concern for the conservation of local ways of life, traditions, and religious space, which are intangible culture (Shinawatra, 2004: 9). The nation should conserve not only its tangible but its intangible cultural heritage including traditions, customs, history, literatures and languages, music, folklore, religions, and local ways of life. The national charter for the conservation and management of the cultural heritage of Thailand should be drawn up as a reference for the conservation of both Thais' tangible and intangible cultural heritage.

To accomplish this, Thai society should have a clear mutual understanding of the term 'culture.' It should evolve collective ideas (common ideas) of Thai culture and its elements as well as develop a shared vision of an approach to sustaining Thai culture.

It is time for Thai society to develop its own charter for the conservation and management of cultural heritage so that its constituents -- government and local administrators, academics, and the Ministry of Culture, for example - will have their own guidelines for the management of Thai cultural heritage in keeping with international conservation standards. The charter will allow the participation of the constituents in preserving and sustaining customs, local knowledge, arts or good culture, as encouraged by the Constitution of The Kingdom of Thailand of 1997, Section 46.

The next question is, "Who should be responsible for drawing up this charter?' It should be an organization that has adequate budget and understanding of cultural heritage. The organization should be associated with Thai cultural heritage and be able to coordinate with local residents, governmental bureaus, and international agencies (the Ministry of Culture and UNESCO). There are five organizations with these qualifications, including:

- The Office of Environmental Policy and Planning (the government bureau now coordinating with the Thai regional office of UNESCO);

- The Society for the Conservation of National Treasures and the Environment (SCONTE - a non-government organization established by the Thailand Environment Foundation); 
- Thailand Cultural Environment Fund (CEF - a non-government organization established by the Thailand Environment Foundation);

- The Arts and Architecture Conservation Committee of the Association of Siamese Architects (ASA - a nongovernment organization); and

- The International Council on Monuments and Sites (ICOMOS Thailand - an international non-governmental organization - with international committees, including the Thai ICMOS committee — advising UNESCO on cultural properties.)

Among these organizations, ICOMOS might be the most suitable delegate. It appears to be able to bring together other public and private organizations and individuals to participate in drawing up the Charter for the Conservation and Management of Cultural Heritage of Thailand.

\section{The Charter and Anthropological Researchers}

From an anthropological standpoint, there are questions concerning how to raise Thai society's awareness of cultural significance; how the society will exploit its cultural resources as a tool for the nation's development; how to evolve collective ideas of researchers; and how to develop a cultural research database from the participation of every constituent across the country.
A cultural data, information and research network as a center of collective information about Thai culture might be the answer to the above questions. However, the center should provide potentially rich resources for research at every level and be approachable for every interested organization and individual with ethics, respect, and professionalism.

The Charter for Cultural Heritage Conservation and Management of Thailand is a good start for the management of the nation's cultural resources. It is also another answer to those questions in that it will help to set a direction for integrated or synthetic anthropological research. Under the supervision of the Fine Arts Department, the Ministry of Culture, and other associated government bureaus, the charter will help to enable the connection of research - by organizations, such as the National Research Council of Thailand, universities and other educational institutions - to future policy for national development. In effect, the Charter will help to promote integrated synthetic research, which the Philosophy Division of the National Research Council encourages, in addition to today's pure research.

\section{References}

Intharawut, Phasuk. 2005. Suvarnbhumi Chak Lukthan Borankhadi (Suvarnbhumi from the Archaeological Evidence). Bangkok: The Department of Archaeology, Silpakorn University. [In Thai]. Jumsai, Sumet. 1997. NAGA Cultural Origins in Siam and the West Pacific. Bangkok: Chalermnit Press and DD Books. [In Thai]. 
Phumisak, Jit. 1976. Khwampenma Khong Kham Sayam Thai Lao Lae Khom Lae Laksana Thangkansangkhom Khong Duchat (Etymology of the terms Siam, Thai, Lao and Khom, and the social characteristics of ethnonyms), Forward by Charnvit Kasetsiri. Bangkok: Social Sciences Association of Thailand. [In Thai].

Shinawatra, Weeraphan. 2004. The Problems and Conception of the Conservation of Architectural Heritage in the Asia Pacific. Paper presented at the Seminar for the Development of the Anthropological Researchers:Integrating-Approach Research for the Conservation and Development of the Northern Old Town. 15-17 October 2004, Chiangmai. [In Thai].

Wallipodom, Srisak. 2001. Phattanakarn Thang Sungkhom Wattanatham Thai (Thai Socio-Cultural Development). $2^{\text {nd }}$ ed. Bangkok: Amarin Printing. [In Thai]. 